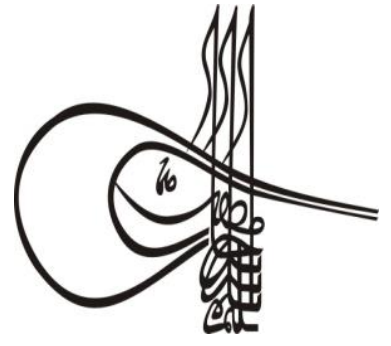

\section{Turkísh Studies \\ Social Sciences}

Volume 14 Issue 3, 2019, p. 653-666

DOI: 10.29228/TurkishStudies.22826

ISSN: 2667-5617

Skopje/MACEDONIA-Ankara/TURKEY

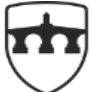

INTERNATIONAL BALKAN UNIVERSITY

EXCELLENCE FOR THE FUTUR IBU.EDU.MK

Research Article / Araştırma Makalesi

ArticleInfo/MakaleBilgisi

VAccepted/Kabul: 10.06 .2019

This article was checked by iThenticate.

\title{
EGZERSİDE DAVRANIŞSAL (MOTIVASYONEL) DÜZENLEMELER İLE WELLNESS ALGISI: SPOR BİLİMLERİ FAKÜLTESİ ÖĞRENCİLERİ ÖRNEĞİ
}

\author{
Burcu GÜVENDİ - Gönül TEKKURŞUN DEMIRR ${ }^{* *}$ - Suzan DAL $L^{* * *}$
}

\begin{abstract}
öz
Araştırmanın amac1 spor bilimleri fakültesi öğrencilerinin egzersizde davranışsal düzenlemeleri ve wellness algılarının incelenmesidir. Arasstırmanın örneklemini iki farklı devlet üniversitesinin spor bilimleri fakültesi öğrencilerinden fiziksel aktiviteye düzenli katılım sağlayan 149 kadın, 212 erkek olmak üzere toplamda 361 üniversite öğrencisi oluşturmaktadır. Veri toplama aracı olarak, "Egzersizde Davranışsal Düzenlemeler Ölçeği” ve "İyilik hali (Welness) Algısı Ölçeği” kullanılmıştır. Verilerin analizinde, betimleyici analizler, pearsonkorelasyon, t-testiveanovaanalizleri kullanılmıştır. Çalışmada egzersizde davranışsal düzenlemeler ölçeğinin güdülenmeme alt boyutu ile wellness ölçeğinin fiziksel wellness alt boyutu arasında $(r=.-103)$ negatif yönde; dişsal düzenleme ile ruhani wellness arasında $(r=.110)$ ise pozitif yönde düşük düzeyde anlamlı ilişki olduğu tespit edilmiștir. Cinsiyete göre egzersizde davranışsal düzenleme alt boyutlarında erkeklerin lehine anlamlı farklılık görülmüștür. Öğrencilerin yaşadığı yere göre, içe atımla düzenleme alt boyutunda ve sosyal wellness alt boyutunda anlamlı farklılık tespit edilmiştir Öğrencilerin egzersiz yapma ile ilgili olumlu algı oluşturması ve egzersize katılımı arttıkça fiziksel sağlıklarının da arttığı görülmüsstür. Öğrencilerin yaşadığı yerin, egzersize katılım motivasyonlarını ve wellness düzeylerini etkilediği özellikle ailesinin yanında yaşayan öğrencilerin daha sosyal olduğu belirlenmiştir. Erkeklerin egzersize katılımda kadın öğrencilere göre daha aktif rol aldığı görülmüştür. Bu çalışma sonuçları ile öğrencilerin
\end{abstract}

Arş. Gör. Dr., İstanbul Üniversitesi Cerrahpaşa Spor Bilimleri Fakültesi, E-posta: burcu.guvendi@istanbul.edu.tr

Arş. Gör., Gazi Üniversitesi Spor Bilimleri Fakültesi, E-posta: gonultekkursun@gazi.edu.tr

Öğr. Gör., İstanbul Üniversitesi Yabancı Diller Bölümü, E-posta: suzann.dal@ gmail.com 
üniversite yaşamlarında özellikle k1z öğrenciler ve öğrenci evi ile yurtlarda kalan öğrenciler için egzersiz yapabilecekleri ortamlarının yoğunlaştırılması ve çeşitli aktiviteler ile egzersizlere katılımlarının içsel olarak arttırılması ile öğrencilerin wellness (iyilik hali) düzeylerinin olumlu yönde gelişmesi sağlanabilir.

Anahtar Kelimeler: Motivasyon, Wellness, Egzersiz, Öğrenci

\title{
BEHAVIOURAL (MOTIVATIONAL) REGULATIONS IN EXERCISE AND WELLNESS PERCEPTION: THE CASE OF STUDENTS OF THE FACULTY OF SPORTS SCIENCES
}

\begin{abstract}
The aim of the study is to investigate the behavioral regulations in exercise and wellness perception of students of the faculty of sports sciences. The sample of the study consisted of 361 students from the faculty of sports sciences of two different state universities, 149 female and 212 male, who attend regular physical activity. As a tool for data collection, "Behavioral Regulations in Exercise Questionnaire" and "Wellness Self-Perceptions Scale " were used. Descriptive analysis, pearson correlation, t-test and anova analysis were used to analyze the data. In the study, a low level significant relationship was identified in the negative direction $(\mathrm{r}=.-103)$ between the motivation sub-dimension of behavioral regulations in exercise questionnaire and physical wellness sub-dimension of wellness scale; and in the positive direction $(\mathrm{r}=.110)$ between external regulation and spiritual wellness. There was a significant difference in favor of males in sub-dimensions of behavioral regulations in exercise according to gender. A significant difference was found in the sub-dimensions of regulation by introjection social wellness according to where students live. It has been observed that as the students create a positive perception about exercise and their participation in exercise increases, their physical health also increases. It was determined that where students live has an impact on their motivation to participate in exercise and wellness levels, and the students living with their families are more social. It was observed that the male students undertake a more active role in exercise compared to the female students. In the light of the results of this study; we can say that the wellness levels of the students in their university life can be developed in a positive way by providing more environment for exercise especially for the female students and the students living in student homes and dormitories and by increasing their participation in exercises internally via various activities.
\end{abstract}

\section{STRUCTURED ABSTRACT}

\section{Introduction}

Exercise is an important factor which provides individuals' weight control, lowers the blood pressure and cholesterol, enhances the perspiration function, raises the individuals' mood, increases selfconfidency and makes the individual forget his daily problems and 
anxieties (Tekkurşun Demir and Türkeli, 2019). Exercise is known to directly affect the psychological variables such as depression, anxiety, self-respect and body image in a positive way.(Özdemir, Cuğ and Çelik, 2010). In the focus of behavioral (motivational) regulations in exercise in which the individuals' being motivated constitutes a plane from autonomic reasons to controllable reasons and various behavioral patterns defined by self-determinants on this plane are present; there are the motivational approaches of the individual (Mullen, Markland and Igledew, 1999). According to the Freewill Theory, the impulses which make us be engaged in various activities bear a multidimensional structure and they are existent on a scale covering various grades, intrinsic motivation, extrinsic motivation (integrated regulation, identificational regulation, introjectional regulation, extrinsic regulation) and amotivation (Deci and Ryan, 2000). When the intrinsic motivation is present, the individuals enjoy being engaged in the activity. The individuals doing exercise are considered intrinsicly motivate as they like the activity they are engaged in, want to learn better and they have a special pleasure transcending themselves in the branch of sports they are interested in (Pelletier, Fortier, Vallerand, tuson and Brière, 1195). In case of intorjectional regulation, the individual needs to exhibit a behaviour to avoid reasons sourcing from ego such as feeling guilty or anxiety and pride. The individuals doing exercise for the reason that they will feel ashamed or guilty otherwise have this kind of motivation. Extrinsic regulation results from rewards which will be given in respond to the behaviour or things which will be lost when the behaviour is not exhibited. The indivviduals doing exercise to be praised or bcause they have health problems constitute examples for this group (Kingston, Horrocks and Hanton, 2006). Amotivation expresses the lack of both intrinsic and extrinsic motivation and represents disappreciation of an activity or the individual does not believe that he will reach the desired results by this activity (Vallerand, DeciandRyan's, 2000).

\section{Method}

The study group of the research consists of a total of 361 university students who continue their education in the Faculty of Sports Sciences of İstanbul University Cerrahpaşa and Gazi University, participate in physical activity regulary and whose average age is = $21,67 \pm 3,44$. Two different scales; one being behavioral regulations scale in exercise and the other being the perceived wellness scale were used as data collecting tools in the research. The collected datawere analysed using SPSS program package. Because of the skewness kurtosis values being between \pm 1 , parametric tests were used in the analysis of the data (Büyüköztürk et al, 2014). In this context, t test, One- Way Analysis of Variance (ANOVA) and Pearson's Product Moment Correlation analysis were used. The level of significance was determined as $\mathrm{p}<0.05$.

\section{Findings}

It has been determined that the physical and social wellness levels which are the subscales of the wellness perception scale and extrinsic regulation and intojectional regulation in the behavioral regulation scale in exercise average points of the students who continue their education in the Faculty of Sports Sciences are higher than the other subscales. 
According to the gender variable of the students, in the points of intrinsic regulation $\left(\mathrm{t}_{(361)}=4,622 ; \mathrm{p}<0,05\right)$, introjectional regulation $\left(\mathrm{t}_{(361)}=3,981 ; \mathrm{p}<0,05\right)$, amotivation $\left(\mathrm{t}_{(361)}=2,092 ; \mathrm{p}<0,05\right)$,- and extrinsic regulation $\left(\mathrm{t}_{(361)}=3,006 ; \mathrm{p}<0,05\right)$ of the behavioral regulation scale, a significant difference was observed.Based on this; it was determined that men's intrinsic regulation points $(\bar{x}=2,16)$ compared to that of women's $(\bar{x}=1,73)$, men's introjectional regulation point's $(\bar{x}=$ $2,01)$ compared to that of women's $(\bar{x}=1,94)$, men's amotivational points $(\bar{x}=2,03)$ compared to that of women's $\left(\bar{x}^{-}=1,84\right)$ and men's extrinsic regulation points $(\bar{x}=2,37)$ compared to that of women's $(\bar{x}$ $=2,18$ ) of the behavioral regulation scale were significantly higher.

Behavioral Regulations in Exercise and Wellness points of the students were examined according to their major using the ANOVA test. As the result of the ANOVA test carried out, significant difference was determined. ${ }^{*}$ Resulting from this analysis, Post-Hoc test statistics was carried out to determine the source of this significant difference appearing between the groups (Tukey HSD).The groups in which the point difference is in their favor are represented with $\left(^{*}\right)$.According to this; in the spiritual wellness subscales of the wellness scale, a significant difference was determined in favor of the students living with their families $\left(\mathrm{F}_{(2,358)}=4,002, \mathrm{p}<0,05\right)$ and in the introjectional regulation scale of the behavioral regulations in exercise, a significant difference was determined in favor of the students staying in dorms $(\mathrm{F}(2,358)=6,064, \mathrm{p}<0,05)$.

According to the correlation analysis carried out, in amotivation in exercise and physical wellness subscales, a significant difference was determined in the negative way in a low level $(r=103, p<0,05)$ and in extrinsic regulation and spiritual wellness subscales, a significant difference was determined in the positive way in a low level $(r=110$, $p<0,05)$. Thus, as the amotivation levels of the students decreases, their physical wellness levels increase. Another result is that as the extrinsic regulations of the students increases, thier spiritual wellness levels increase, too.

\section{Conclusion}

In this research, the behavioral regulations in exercise and wellness perception of the students in the faculty of sports sciences were examined. The results obtained from the research and the discussions related to the results are given below.

It can be said that the students in the faculty of sports sciences participate in the physical activity mostly for external rewards, as their family or friends want them to or not to feel themselves guilty and unsuccessful as their physical and social wellness levels and extrinsic and intojectional regulation levels aare high. According to these findings; it is observed that the participation of the students in the faculty of sports sciences in physical activity contribute both to their physical and social wellness levels no matter with which motivation they participate in the physical activity.

The behavioral (motivational) regulation point averages of the male students are higher to those of the female students. So, according to these results, it can be expressed that male students internally enjoy participating in the exercise more than the femle students, they are 
more conscious about the benefits of doing exercise, they may participate in the exercise because they feel uncomfortable when they do not and can do exercise fort he reward they will get and the praise they will hear and even they may give up doing exercise more quickly than the female students.

The students' place of residence affects their doing sports or various social activities. This situation necessarily reflects to their daily lives and moods. According to the results of of research, it was observed that the students staying in the dormitory participate in the exercise because they feel ashamed when they do not do exercise and not to feel guilt. It also was determined that the wellness average of the students living with their families were higher than the students living in student homes. Then it can be considered that this results from the fact that the students living in student homes have more rental expenses, making friends in a different environment is harder, they have the possibility of spending more time in digital medium and they may not adapt to the city.

According to the correlation analysis, as the amotivation levels of the students decreases, their physical wellness levels increase. Thus, as the students' motivation of participation in the exercise increases, they perceive themselves more healthy physically. What is more, increase of the external reinforcers such as reward or praise in exercise increase the spiritual wellness levels of the students leading to their attachment to the earthly life tightly and their having a purpose in life. When we look at the age range of the students, it can be said that they are in a phase in which they expect attention and support the most, the struggle to make a living has started and they are on the edge of shaping their future. Finally; it has been observed that the students' physical health increases as they form a positive perception of doing exercise and as their participation in the exercise increases. It has been determined that the students' place of residence affects their motivation for participation in exercise and wellness levels, especially the students living with their families are more social. It was observed that the male students undertake a more active role in exercise compared to the female students. In the light of the results of this study; we can say that the wellness levels of the students in their university life can be developed in a positive way by providing more environment for exercise especially for the female students and the students living in student homes and dormitories and by increasing their participation in exercises internally via various activities.

Keywords: Motivation, Wellness, Exercise, Student

\section{Giriş}

Egzersiz, bireylerin kilo kontrolünü sağlayan, kan basıncını ve kolesterolünü düşüren, solunum fonksiyonlarını iyileştiren, bireylerin ruh halini yükselten, özgüveni arttıran, günlük sorun ve kaygılarını unutturan önemli bir faktördür (Tekkurşun Demir ve Türkeli, 2019). Egzersizin depresyon, kayg1, stres, benlik saygısı ve beden imgesi gibi psikolojik değişkenlere doğrudan olumlu yönde etki ettiği bilinmektedir (Özdemir, Cuğ ve Çelik, 2010).

Bireyin motive olmasının özerk nedenlerden kontrol edilebilir nedenlere doğru bir düzlem arz ettiği ve bu düzlemde yer alan özbelirleyiciler tarafından tanımlanmış çeşitli davranış kalıplarının 
bulunduğu “egzersizde davranışsal (motivasyonel) düzenlemeler”'in odak noktasında bireyin motivasyonel yaklaşımları bulunmaktadır (Mullen, Markland ve Ingledew, 1999). Hür İrade kuramına göre, çeşitli aktivitelerle ilgilenmemize sebep olan dürtüler çok boyutlu bir yapı gösterirler ve çeşitli derecelerin olduğu, içsel güdülenme, dişsal güdülenme (bütünleşmiş düzenleme, özdeşimle düzenleme, içeatımla düzenleme, dışsal düzenleme) ve güdülenmeme şeklinde bir skala üzerinde varolurlar (Deci ve Ryan, 2000). İçsel güdülenme yaşandığında bireyler aktiviteyle uğraşmaktan zevk alır. İlgili oldukları etkinliği sevdikleri, daha iyi öğrenmek istedikleri, ilgilendikleri spor dalında kendilerini aşmaktan özel bir haz aldığı için egzersiz yapan bireyler içsel olarak güdülenmiş olarak değerlendirilirler (Pelletier, Fortier, Vallerand, Tuson ve Brière, 1195). İçe atımla düzenleme durumunda birey suçlu hissetmekten ya da endişeden kaçış, gurur gibi egodan kaynaklanan sebeplerle bir davranışı gösterme gereği duyulur. Sporla uğraşmadıklarında mahcup ya da suçlu hissedecekleri için egzersiz yapan bireyler bu türden bir güdülenmeye sahiptir. Dışsal düzenleme ise davranışa verilecek olan ödeüller ya da davranış gerçekleşmediğinde mahrum kalınacak şeyler sebebiyle oluşur. Övgü kazanmak veya sağlıkla ilgili bir sorun yaşadıkları için egzersiz yapan bireyler bu gruba örnek oluştururlar (Kingston, Horrocks ve Hanton, 2006). Güdülenmeme ise, hem içsel hem de dişsal güdülenmenin eksikliğini ifade etmektedir ve bir etkinliğe değer vermemeyi gösterir veya birey bu etkinlikle istediği sonuçlara ulaşacağına inanmamaktadır (Vallerand, DeciandRyan's, 2000).

Arslanve Altay (2009) kişiyie gzersiz davranışına iten nedenleri belirleyen motivasyonel faktörlerin ortaya konması gerektiğini savunmaktadır. Ülkemizde bireylerin egzersize katılımlarında rol oynayan motivasyonel düzenlemelerin belirlenmesine yönelik çalışmalar önem kazanmıştır (Güngörmüş vd., 2014; Kazak, 2004; Toros, Akyüz ve Bayansalduz, 2010). Nitekim literatürde bireylerin egzersiz, spor, fiziksel aktivite ve rekreatif faaliyetlere katılım motivasyonlarının incelendiği araştırmalar yer almaktadır (İlhan ve Gencer, 2013; İlhan, 2009; Kartal, Güvendi, Türksoy ve Altıncı, 2017; Türksoy Işım, Güvendi ve Toros, 2019; Tekkurşun Demir, İlhan, Esentürk ve Kan, 2018; Tekkurşun Demir ve Cicioğlu, 2018; Tekkurşun Demir, Hazar ve Can, 2018). Motivasyon, bireyi amaçları veya hedefleri doğrultusunda harekete geçiren, harekete geçme sürecinde amacı veya hedefi gerçekleştirmek için yönlendiren güçtür (Tekkurşun Demir ve Cicioğlu, 2018). Bir başka deyişle motivasyon amaçsal davranışları ve niyeti harekete geçirirken, amaçsal davranışların tamamlanmasını sağlar (Deci ve Ryan, 2000; Morgan, 2005). Aaltonen vd. (2014)'ne göre, fiziksel uygunluk, ustalık, fiziksel aktivitenin sosyal yönü, psikolojik durumu, eğlence, gönüllülük, diğerlerinden daha iyi olma/görünme ile ilişkili insanların daha kolay motive olduklarını; Hausenblasvd. (2004)'ne göreise, insanlarınsağlık, eğlenmek, başkalarıyla birarada olmak, psikolojik nedenler, kilo kontrolü, kasgelişimi, fiziksel görünüş, fiziksel imaj gibi nedenlerle motive olduklarını belirtmişlerdir. Bireyleri davranışa iten motivasyon kaynakları arasında wellness (esenlik) algısı da yeralmaktadır. Welness; kişinin kas gücü, bilişsel ve ruhsal olarak iyi oluşunun içiçe olması ve eşit miktarda yaşam kalitesini etkileyerek arttırması olarak tanımlanabilir. Son yıllarda gelişmekte olan bir yaklaşım olarak, insanların yaşam tarzını düzenleme ve bu sayede daha kaliteli ve sağlıklı bir yaşam sürme ile başlayarak, hayatın tamamına bir bütün olarak bakabilme sanatı, wellness (esenlik) olarak tanımlanmaktadır (Görgülüer, 1993). Hettler'e göre welness; "kişinin daha başarılı bir varoluş için gerekli olan seçimlerin farkına vardığı ve bu seçimleri yaptığı aktif bir süreçtir." (Steward, 1998).

Günümüzde, bireylerin mental yorgunluk yaşamaları, gençlerin geleceklerini yönlendirecek olan sınavlara hazırlanması yüzünden yeterli zaman ve enerji bulamamaları, modern ulaşım araçlarının kullanılması nedeniyle günlük adım sayısının azalması gibi nedenlerden dolayı insane sağlığının önemli destekçilerinden olan fiziksel aktiviteye katılım çeşitli nedenlere bağlı olarak günden güne azalmaktadır (Tekkurşun Demir ve Cicioğlu, 2018). Öte yandan bireylerin günlük yaşantıların akışına kapılması sonucunda görev ve sorumluluklarını ihmal etmekte, bu durum da yakın gelecekte olmasa bile orta ve uzak gelecekte yaşamlarını olumsuz etkilemektedir. Bu da egzersizde davranışsal (motivasyonel) düzenlemeleri ve wellness algısını olumsuz etkilemektedir. Buna göre, araştırmada gelecek nesillerin emanet edileceği ve çeşitli kurumlarda önemli noktalarda çalışacak olan spor 
bilimleri fakültesi öğrencilerinin egzersizde davranışsal (motivasyonel) düzenlemeleri ile welness algısının incelenmesi önemlidir. Bu nedenle araştırmada spor bilimleri fakültesi öğrencilerinin çeşitli demografik özellikleri açısından egzersizdedavranışsal (motivasyonel) düzenlemeleri ile welness algısının incelenmesi amaçlanmıştır.

\section{Yöntem}

\section{Araștırma Grubu}

Araştırmanın çalışma grubunu İstanbul Üniversitesi Cerrahpaşa ve Gazi üniversitesi spor bilimleri fakültesinde öğrenim gören ve fiziksel aktiviteye düzenli katılım sağlayan yaş ort=

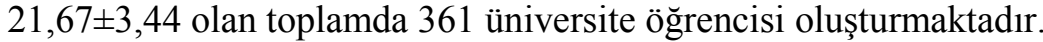

Tablo 1. Katılımcıların demografik özellikleri

\begin{tabular}{|c|c|c|}
\hline Yaş & $\mathbf{F}$ & $\%$ \\
\hline \multirow{3}{*}{$\begin{array}{l}18-19 \\
20-21 \\
23 \text { ve üzeri }\end{array}$} & 157 & 43,5 \\
\hline & 134 & 37,1 \\
\hline & 70 & 19,4 \\
\hline Cinsiyeti & $\mathbf{F}$ & $\%$ \\
\hline \multirow{2}{*}{$\begin{array}{l}\text { Kadın } \\
\text { Erkek }\end{array}$} & 149 & 41,3 \\
\hline & 212 & 58,7 \\
\hline Yaşadığı yer & $\mathbf{F}$ & $\%$ \\
\hline \multirow{3}{*}{$\begin{array}{l}\text { Aile Yanı } \\
\text { Yurt } \\
\text { Öğrenci Evi }\end{array}$} & 258 & 71,5 \\
\hline & 59 & 16,3 \\
\hline & 44 & 12,2 \\
\hline Bölümü & $\mathbf{F}$ & $\%$ \\
\hline \multirow{5}{*}{$\begin{array}{l}\text { Beden Eğitimi Öğretmenliği } \\
\text { Spor Yöneticiliği } \\
\text { Antrenörlük } \\
\text { Rekreasyon } \\
\text { Ortak Program }\end{array}$} & 54 & 15,0 \\
\hline & 103 & 28,5 \\
\hline & 78 & 21,6 \\
\hline & 58 & 16,1 \\
\hline & 68 & 18,8 \\
\hline Toplam & 361 & 100 \\
\hline
\end{tabular}

Örneklem grubunu oluşturan öğrencilerin çoğunluğunun ailesinin yanında yaşadığı $(\% 71,5)$ ve spor yöneticiliği bölümü öğrencilerinin $(\% 28,5)$ ağırlıkta olduğu görülmektedir.

\section{Verileri Toplama Araçları}

Araştırmada veri toplama aracı olarak egzersizde davranışsal düzenlemeler ölçeği ve algılanan wellness ölçeği olmak üzere iki farklı ölçek kullanılmıştır.

Egzersizde Davranışsal Düzenlemeler Ölçeği-2: Ölçeğin ilk versiyonu olan EDDÖ, Mullan, Markland ve Ingledew (1997) tarafından geliştirilmiş olup Markland ve Tobin (2004) tarafından revize edilerek "EDDÖ-2" adını almıştır. Ersöz, Aşçı ve Altıparmak tarafindan Türkçe geçerlilik ve güvenirlik çalışması yapılmış olup ölçek içsel düzenleme, içe atımla düzenleme, dışsal düzenleme ve güdülenmeme olmak üzere dört alt boyut ve 19 maddeden oluşmaktadır. Dışsal düzenleme (örn: Başkaları egzersiz yapmam gerektiğini söyledikleri için egzersiz yaparım) alt boyutu dört ve içsel düzenleme (örn: Eğlenceli olduğu için egzersiz yaparım) alt boyutu yedi maddeden, içe atımla düzenleme (örn: Egzersiz yapmadığımda kendimi suçlu hissederim) ve güdülenmeme (örneğin: Neden egzersiz yapmam gerektiğini anlamıyorum) alt boyutları ise 4 maddeden oluşmaktadır. EDDÖ-2, "kesinlikle doğru değil", "bazen doğru" ve "kesinlikle doğru" derecelerinden oluşan 0-4 arasında puanlaması olan 5'li likert tipi bir ölçektir.

İyilik hali (Wellness) Ölçeği: Corbin ve ark. (2006) tarafından geliştirilmiş olan ölçeğin Türkçe uyarlaması Odabaş (2017) tarafindan yapılmıştır. Ölçek "Kesinlikle Katılmıyorum, 
Katılmıyorum, Katıliyorum, Kesinlikle Katıliyorum' ifadesinden oluşan dörtlü Likert şeklindedir ve 15 madde ve beş alt boyuttan oluşmaktadır. Ölçeğin alt boyutları Duygusal İyilik, Zihinsel İyilik, Fiziksel İyilik, Sosyal İyilik ve Ruhani (Manevi) İyilik şeklindedir. Ölçekte ilk üç soru (1-3) duygusal iyilik (wellness) algısını, sonraki üç soru (4-6) entelektüel iyilik (wellness) algısını, sonraki sorular sırası ile (7-9) fiziksel iyilik (wellness) algısını, (10-12) sosyal iyilik (wellness) algısını ve son üç soru (13-15) ruhani iyilik (wellness) algısını ölçmektedir. Ölçekte "çoğu zaman mutluyumdur, dünyadaki olaylardan daima haberdarımdır, fiziksel sağlığım iyidir, aileme sıkıca bağlıyımdır, hayatta her zaman bir amacım vardır" şeklinde sorular yer almaktadır. Ölçekten alınan yüksek puan iyilik (wellness) algısının yüksek olduğunu göstermektedir. Ölçeğin güvenilirlik değeri 0.86 olarak bulunmuştur.

\section{Verilerin analizi}

Elde edilen veriler SPSS paket programı kullanılarak çözümlenmiştir. Ölçeğin çarpıklık basıklık değerlerinin \pm 1 arasında olması sonucu, verilerin analizinde parametrik testlerden yararlanılmıştır (Büyüköztürk vd., 2014). Bu bağlamda verilerin analizinde ttesti, Tek Faktörlü Varyans Analizi (ANOVA) ve Pearson Momentler Çarpımı Korelasyon analizi kullanılmıştır. Anlamlılık düzeyi $\mathrm{p}<0.05$ olarak belirlenmiştir.

\section{Bulgular}

$\mathrm{Bu}$ çalışma Spor bilimleri fakültesi öğrencilerinin egzersizde davranışsal (motivasyonel) düzenlemeleri ve wellness düzeylerinin bazı bağımsız değişkenlere göre incelenmesi ve aralarındaki ilişkinin incelenmesi amacıyla yapılmıştır.

Tablo 2. Ölçeklere Ait Ortalama Puanlar

\begin{tabular}{c|c|c|c|c|c|c}
\hline \multirow{2}{*}{ Ölçekler } & Alt Boyutlar & $\mathbf{n}$ & Min. & Max. & Ort. & Std. Sp. \\
\hline \multirow{2}{*}{$\begin{array}{c}\text { Egzersizde } \\
\text { Davranışsal } \\
\text { Düzenlemeler } \\
\text { Ölçeği }\end{array}$} & İçsel Düzenleme & 361 &, 71 & 4,00 & 1,90 &, 576 \\
\cline { 2 - 7 } & İçe Atımla Düzenleme & 361 &, 75 & 4,00 & 2,07 &, 539 \\
\cline { 2 - 7 } & Güdülenmeme & 361 &, 00 & 4,00 & 1,95 &, 610 \\
\cline { 2 - 8 } & Dişsal Düzenleme & 361 &, 75 & 4,00 & 2,29 &, 590 \\
\cline { 2 - 7 } & Duygusal Wellness & 361 & 1,00 & 4,00 & 3,00 &, 594 \\
\cline { 2 - 7 } $\begin{array}{c}\text { İyilik hali } \\
\text { (Wellness) Ölçeği }\end{array}$ & Zihinsel Wellness & 361 & 1,33 & 4,00 & 3,16 &, 507 \\
\cline { 2 - 7 } & Fiziksel Wellness & 361 & 1,67 & 4,00 & 3,46 &, 544 \\
\cline { 2 - 7 } & Sosyal Wellness & 361 & 2,00 & 4,00 & 3,33 &, 551 \\
\hline
\end{tabular}

Tablo 2'e göre, Spor bilimleri fakültesinde okuyan öğrencilerin wellness algısı ölçeği alt boyutları olan fiziksel ve sosyal wellness düzeyleri ile egzersizde davranışsal düzenleme ölçeğinde dışsal düzenleme ve içe atımla düzenleme ortalama puanlarının diğer alt boyutlardan daha yüksek olduğu belirlenmiştir. 
Tablo 3. Cinsiyet Değişkenine Göre Egzersizde Davranışsal Düzenlemeler ve Wellness Algısı Ölçeği t testi Sonuçları

\begin{tabular}{|c|c|c|c|c|c|c|}
\hline $\begin{array}{c}\text { Egzersizde Davranışsal } \\
\text { Düzenlemeler Ölç̧̆gi }\end{array}$ & Cinsiyet & $\mathbf{n}$ & Ort. & Std. Sp. & $\mathbf{t}$ & $\mathbf{p}$ \\
\hline \multirow{2}{*}{ İçsel Düzenleme } & Kadın & 149 & 1,73 & ,486 & \multirow{2}{*}{$-4,622$} & \multirow{2}{*}{,000 } \\
\hline & Erkek & 212 & 2,01 & ,608 & & \\
\hline \multirow{2}{*}{ İçe Atımla Düzenleme } & Kadın & 149 & 1,94 &, 483 & \multirow{2}{*}{$-3,981$} & \multirow{2}{*}{,000 } \\
\hline & Erkek & 212 & 2,16 &, 558 & & \\
\hline \multirow{2}{*}{ Güdülenmeme } & Kadın & 149 & 1,84 &, 546 & \multirow{2}{*}{$-2,902$} & \multirow{2}{*}{,004 } \\
\hline & Erkek & 212 & 2,03 & ,642 & & \\
\hline \multirow{2}{*}{ Dışsal Düzenleme } & Kadın & 149 & 2,18 &, 579 & \multirow{2}{*}{$-3,006$} & \multirow{2}{*}{,003 } \\
\hline & Erkek & 212 & 2,37 & ,586 & & \\
\hline
\end{tabular}

Tablo 3'de, öğrencilerin cinsiyet değişkenine göre egzersizde davranışsal düzenleme ölçeğinin; içsel düzenleme $\left(\mathrm{t}_{(361)}=-4,622 ; \mathrm{p}<0,05\right)$, içe atımla düzenleme $\left(\mathrm{t}_{(361)}=-3,981 ; \mathrm{p}<0,05\right)$, güdülenmeme $\left(\mathrm{t}_{(361)}=-2,902 ; \mathrm{p}<0,05\right)$ ve dişsal düzenleme $\left(\mathrm{t}_{(361)}=-3,006 ; \mathrm{p}<0,05\right)$ puanlarında anlamlı farklılık görülmüştür. Buna göre, erkeklerin içsel düzenleme puanlarının $(\bar{x}=2,01)$ kadınlara $(\bar{x}=1,73)$; erkeklerin içe atımla düzenleme puanlarının $(\bar{x}=2,16)$ kadınlara $(\bar{x}=1,94)$; erkeklerin güdülenmeme puanlarının $(\bar{x}=2,03)$ kadınlara $(\bar{x}=1,84)$ ve erkeklerin dışsal düzenleme puanlarının $(\bar{x}=2,37)$ kadınlara $(\bar{x}=2,18)$ göre anlamlı düzeyde yüksek olduğu saptanmıştır $(\mathrm{p}<0,05)$.

Tablo 4. Yaşadığı Yere Göre Egzersizde Davranışsal Düzenlemeler ve Wellness Algısı Ölçeği ANOVA Analiz Sonuçları

\begin{tabular}{|c|c|c|c|c|c|c|c|c|}
\hline \multicolumn{3}{|c|}{ Ölçekler } & $\mathbf{n}$ & Ort. & Std.Sp. & $\mathbf{F}$ & $\mathbf{P}$ & Tukey \\
\hline \multirow{3}{*}{$\begin{array}{c}\text { Egzersizde } \\
\text { Davranışsal } \\
\text { Düzenlemeler } \\
\text { Ölçeği }\end{array}$} & \multirow{3}{*}{$\begin{array}{l}\text { İçe Atımla } \\
\text { Düzenleme }\end{array}$} & Aile Yanı & 258 & 2,03 &, 515 & \multirow{3}{*}{4,002} & \multirow{3}{*}{,019 } & \multirow{3}{*}{$\mathrm{Y} * / \mathrm{A}$} \\
\hline & & Yurt & 59 & 2,25 & 675 & & & \\
\hline & & Öğrenci Evi & 44 & 2,10 & ,429 & & & \\
\hline \multirow{3}{*}{$\begin{array}{c}\text { İyilik hali } \\
\text { (Wellness) Ölçeği }\end{array}$} & \multirow{3}{*}{ Ruhani Wellness } & Aile Yanı & 258 & 3,39 & ,517 & \multirow{3}{*}{6,064} & \multirow{3}{*}{, 003} & \multirow{3}{*}{$\mathrm{A}^{* / O ̈}$} \\
\hline & & Yurt & 59 & 3,23 & ,577 & & & \\
\hline & & Öğrenci Evi & 44 & 3,12 & ,643 & & & \\
\hline
\end{tabular}

Tablo 4'te, Egzersizde Davranışsal Düzenlemeler ile Wellness puanları öğrencilerin okudukları bölüm açısından ANOVA testi ile incelenmiştir. Yapılan ANOVA analizi sonucunda anlamlı farklılık tespit edilmiştir* Bu çözümleme sonucunda gruplar arasında beliren anlamlı farkın kaynağını belirlemek amacıyla, Post-Hoc test istatistikleri uygulanmıştır (Tukey HSD). Puan farkı lehine olan yüksek gruplar $\left(^{*}\right)$ ile gösterilmiştir. Buna göre wellness ölçeğinin; ruhani wellness alt boyutlarında ailesinin yanında kalan öğrenciler lehine $\left(\mathrm{F}_{(2,358)}=4,002, \mathrm{p}<0,05\right)$ ve egzersizde davranışsal düzenlemeler ölçeğinin ise içe atımla düzenleme boyutunda yurtta kalan öğrencilerin lehine anlamlı farkl11ık tespit edilmiştir $\left(\mathrm{F}_{(2,358)}=6,064, \mathrm{p}<0,05\right)$. 
Tablo 5.Ölçeklere Ait Korelasyon Analizi Sonuçları

\begin{tabular}{|c|c|c|c|c|c|c|}
\hline \multicolumn{2}{|l|}{ Ölçekler } & $\begin{array}{l}\text { Duygusal } \\
\text { Wellness }\end{array}$ & $\begin{array}{l}\text { Zihinsel } \\
\text { Wellness }\end{array}$ & $\begin{array}{c}\text { Fiziksel } \\
\text { Wellness }\end{array}$ & $\begin{array}{c}\text { Sosyal } \\
\text { Wellness }\end{array}$ & $\begin{array}{c}\text { Ruhani } \\
\text { Wellness }\end{array}$ \\
\hline \multirow{3}{*}{ İçsel Düzenleme } & $\mathrm{r}$ &,- 006 &,- 072 &,- 099 &,- 050 & ,009 \\
\hline & $\mathrm{p}$ & ,911 &, 171 & ,062 & ,339 &, 864 \\
\hline & $\mathrm{n}$ & 361 & 361 & 361 & 361 & 361 \\
\hline \multirow{3}{*}{ İçe Atımla Düzenleme } & $\mathrm{r}$ &,- 043 &,- 058 &,- 094 &,- 028 & ,007 \\
\hline & $\mathrm{p}$ & ,410 & ,271 & ,073 &, 591 & ,894 \\
\hline & $\mathrm{n}$ & 361 & 361 & 361 & 361 & 361 \\
\hline \multirow{3}{*}{ Güdülenmeme } & $\mathrm{r}$ &,- 009 &,- 006 &,$- \mathbf{1 0 3}^{*}$ &,- 006 & ,023 \\
\hline & $\mathrm{p}$ &, 858 & ,905 &, 050 &, 915 & ,657 \\
\hline & $\mathrm{n}$ & 361 & 361 & 361 & 361 & 361 \\
\hline \multirow{3}{*}{ Dişsal Düzenleme } & $\mathrm{r}$ &, 052 &,- 037 & ,002 & ,038 &, $\mathbf{1 1 0}^{*}$ \\
\hline & $\mathrm{p}$ &, 325 &, 487 & ,976 & ,467 & ,036 \\
\hline & $\mathrm{n}$ & 361 & 361 & 361 & 361 & 361 \\
\hline
\end{tabular}

Tablo 5'de yapılan korelasyon analizine göre, egzersizde güdülenmeme ile fiziksel wellness alt boyutları negatif yönde düşük düzeyde $(\mathrm{r}=-103, \mathrm{p}<0,05)$; dışsal düzenleme ile ruhani wellness alt boyutları arasında $(\mathrm{r}=110, \mathrm{p}<0,05)$ pozitif yönde düşük düzeyde anlamlı ilişki saptanmıştır. Buna göre, öğrencilerin egzersizde güdülenmeme düzeyleri azaldıkça fiziksel wellness düzeyleri artmaktadır. Diğer bir sonuç ise öğrencilerin dışsal düzenlemeleri arttıkça ise ruhani wellness'ları da artmaktadır.

\section{Tartışma, Sonuç ve Öneriler}

$\mathrm{Bu}$ araştırmada spor bilimleri fakültesi öğrencilerinin egzersizde davranışsal düzenlemeleri ve wellness algıları incelenmiştir. Araştırmada elde edilen sonuçlar ve sonuçlara ilişkin tartışmalar aşağıda verilmiştir.

Spor bilimleri fakültesinde okuyan öğrencilerin fiziksel ve sosyal wellness düzeyleriyle birlikte dışsal düzenleme ve içe atımla düzenleme düzeylerinin yüksek olması öğrencilerin çoğunlukla dışsal ödüller için, ailesi ya da arkadaşları istediği için ve bununla birlikte öğrencinin egzersizi yapmadığında kendini suçlu ve başarısız hissetmemek adına fiziksel aktiviteye katılım gösterdiği söylenebilir. Bu bulgulara göre, hangi motivasyonla fiziksel aktiviteye katılırsa katılsın spor bilimleri öğrencilerinin fiziksel aktivite yapıyor olması hem fiziksel hem de sosyal wellnesslarının yüksek olmasına katkı sağladığı görülmektedir. Çalışmamız ile benzer araştırmalara bakıldığında; Özdemir, Özşaker ve Ersöz (2016) tarafından üniversite öğrencileri üzerinde yapılan çalışmada öğrencilerin güdüsel yönelimlerinde en yüksek değeri içsel ve içe atımla düzenleme alt ölçekleri alırken; en düşük değerleri dışsal düzenleme ve güdülenmeme alt ölçeklerinin aldığı belirlenmiştir. Ayrıca katılımcıların psikolojik iyi oluş düzeyi incelendiğinde ortalamanın yüksek olduğu sonucuna ulaşılmıştır. Wininger (2007), egzersize katılan bireylerin egzersiz yapma nedenlerinin suçluluk duygusu, sosyal onay, kişisel hedefler ve içsel güdüler gibi çok boyutlu olduğunu ve bu yüzden katılımcıların egzersizde güdüsel düzenlemelerinin belirlenmesi gerektiğini belirtmiştir. 
Erkek öğrencilerin egzersizde davranışsal (motivasyonel) düzenleme puan ortalamaları kız öğrencilerden daha yüksektir. $\mathrm{O}$ halde bu sonuçlara göre, erkek öğrenciler egzersize katılımdan kız öğrencilere göre içsel olarak daha fazla zevk aldıkları ve egzersizin yararının daha fazla farkında oldukları ve egzersiz yapmadıklarında kendilerini huzursuz hissettikleri için egzersize katılabilecekleri gibi egzersizi alacakları ödül ve duyacakları övgü içinde yapabildikleri hatta kız öğrencilere göre egzersizden daha çabuk vazgeçebilecekleri ifade edilebilir. Bu bulgulara benzer olarak Özdemir, Özşaker ve Ersöz (2016) tarafından yapılan çalışmada içe atım ve dışsal düzenleme ile güdülenmeme konusunda kadınlar erkeklere göre daha düşük puanlar elde ettikleri görülmüştür. Gümüş (2017)'nin yaptığı çalışmada cinsiyete göre egzersizde davranışsal düzenlemeler ölçeğinde anlamlı farklılığa rastlanılmamıştır.

Öğrencilerin yaşadıkları yerlerde spor yapmalarını ya da çeşitli sosyal faaliyetlerini etkilemektedir. $\mathrm{Bu}$ durumda ister istemez günlük hayatlarına ve ruh hallerine de yansımaktadır.Araştırma sonuçlarımıza göre,yurtta kalan öğrencilerin egzersizi yapmadığında kendine karşı mahcubiyet hissettiği ve suçluluk duygusu yaşamamak adına egzersize katıldığ 1 görülmüştür. Ailesinin yanında kalan ögrencilerin ise sosyal wellness ortalamasının öğrenci evinde kalanlardan daha yüksek olduğu belirlenmiştir. Bu duruma öğrenci evlerinde kalanların ayrıca kira ödemeleri masraflarının daha fazla olması, farklı bir ortamda arkadaş edinmenin zorlukları, dijital ortamda daha fazla zaman geçirme ihtimali ya da şehre alışamama gibi nedenlerden kaynaklanabileceği düşünülebilir. Alan yazında yapılan bir çalışmada öğrencilerin egzersize katılmadıklarında zaman geçirmek adına çoğunlukla başvurduğu düşünüldüğü internet kullanımının iyilik hali ile ilişkisi araştırılmış ve Çağır (2010) öğrencilerin internet kullanımlarının problemli olduğunu, yalnızlık düzeylerinin orta seviyede olduğunu ve esenlik hallerinin ise düşük olduğunu ayrıca öğrencilerin problemli internet kullanımları ile algılanan esenlik halleri arasında ise negatif yönde anlamlı ilişki bulunduğunu belirtmiştir.

Korelasyon analizine göre, öğrencilerin egzersizde güdülenmeme düzeyleri azaldıkça fiziksel wellness düzeyleri artmaktadır. Dışsal düzenlemeleri arttıkça ise ruhani wellness'ları da artmaktadır. Buna göre, öğrencilerin egzersize katılım motivasyonları arttıkça fiziksel olarak kendilerini daha sağlıklı algıladıkları görülmüştür. Ayrıca egzersizde ödül ve övgü gibi dışsal pekiştireçlerin artması öğrencilerin dünya hayatına sıkıca bağlanması ve hayatta bir amaç sahibi olması anlamına gelen ruhani wellness düzeylerini arttırmaktadır. Öğrencilerin yaş aralığına bakıldığında en fazla ilgi ve destek bekledikleri, maddi olarak geçinme telaşına girilmiş, geleceğine yön verme aşamasında olduğu dönemlerde oldukları söylenebilir. Bu bulgulara benzer olarak Özdemir, Özşaker ve Ersöz (2016) tarafından yapılan çalışmada içe atımla düzenleme ile psikolojik iyi oluş arasında pozitif; dışsal düzenleme ve güdülenmeme arasında ise negatif ilişki bulunmuştur. Korkut-Owen, Demirbaş-Çelik ve Doğan (2017)'nin çalışmasında iyilik hali ile psikolojik sağlamlık arasında olumlu yönde orta düzeyde ilişki bulunmaktadır. Ingledew ve Markland (2008) tarafindan genç egzersiz katılımcıları üzerinde yapılan çalışmada, hem içsel hem de özdeşimle düzenlemenin egzersiz davranışını öngörmede etkili olduğu; buna karsın ne dışsal ne de içe atımla düzenlemenin egzersiz davranışına dair herhangi bir öngörüde bulanamadığı ortaya konulmuştur

Sonuç olarak, öğrencilerin egzersiz yapma ile ilgili olumlu algı oluşturması ve egzersize katılımı arttıkça fiziksel sağlıklarının da arttığı görülmüştür. Öğrencilerin yaşadığ1 yerin; egzersize katılım motivasyonlarını ve wellness düzeylerini etkilediği özellikle ailesinin yanında yaşayan öğrencilerin daha sosyal olduğu belirlenmiştir. Erkeklerin egzersize katılımda kadın öğrencilere göre daha aktif rol aldığı görülmüştür. Kılıç ve Balta (2019) tarafindan Üniversite öğrenncileri üzerinde yapılan çalışmada sağlıklı yaşam bilincinin gelişmesi için, üniversiteler, yerel yönetimler, herkes için spor federasyonu ve toplumumuzun tüm kurum ve kuruluşlarıyla bütün toplumu kucaklayan projeler üretilerek daha sağlıklı yaşam biçimi davranışları eğitimlerin düzenlenmesi gerektiğine vurgu yapılmıştır. Bu çalışma sonuçları ile öğrencilerin üniversite yaşamlarında özellikle kız öğrenciler ve öğrenci evi ile yurtlarda kalan öğrenciler için egzersiz yapabilecekleri ortamlarının yoğunlaştırılması 
ve çeşitli aktiviteler ile egzersizlere katılımlarının içsel olarak arttırılması ile öğrencilerin wellness (iyilik hali) düzeylerinin olumlu yönde gelişmesi sağlanabilir.

\section{KAYNAKÇA}

Aaltonen, S.,Rottensteiner, M., Kaprio, J. \&Kujala, U.M. (2014). MotivesForPhysical Activity Among Active andInactivePersons in TheirMid-Thirties. ScandinavianJournal of Medicine\&Science in Sports, 24(4),727-735.

Arslan, Y. \& Altay, F. (2009). İlköğretim Okul Takımlarındaki Erkek Öğrencilerin Spora Katılım Motivasyonlarının İncelenmesi. Celal Bayar Üniversitesi Beden Eğitimi ve Spor Bilimleri Dergisi, 4(2), 59-66.

Büyüköztürk, Ş., K1lıç Çakmak, E., Akgün, Ö.E., Karadeniz, Ş. \& Demirel, F. (2014). Bilimsel Araştırma Yöntemleri. Ankara: Pegem Yayınları.

Çağır, G. (2010). Lise ve Üniversite Öğrencilerinin Problemli İnternet Kullanım Düzeyleri İle Algılanan Esenlik Halleri ve Yalnızlık Düzeyleri Arasındaki İlişki. (YayınlanmamışYüksek Lisans Tezi). Balıkesir Üniversitesi, Sağlık Bilimleri Enstitüsü, Balıkesir.

Deci, E.L. \&Ryan, R.M. (2000). The "What" and "Why" of GoalPursuits: Human NeedsandTheSelfdetermination of Behavior. PsychologicalInquiry, 11(4), 227-268.

Ersöz, G., Aşçı, H. \& Altıparmak, E. (2012). Egzersizde Davranışsal Düzenlemeler Ölçeği-2: Geçerlilik ve Güvenilirlik Çalışması. Türkiye Klinkleri J Sports Sci, 4(1), 22-31.

Görgülüer, C. (1993). Orta Dereceli Okullarda Görev Yapan Beden Eğitimi Öğretmenlerinin Ders Dışı Egzersiz Faaliyetlerinin Değerlendirilmesi. (Yayımlanmamış Yüksek Lisans Tezi). Selçuk Üniversitesi, Sağlık Bilimleri Enstitüsü, Konya.

Gümüş, E. (2017). Egzersizde Motivasyonel Düzenlemelerin ve Sosyal Fizik Kaygı Düzeyinin, Yaşam Kalitesi Bağlamında İncelenmesi. (Yayımlanmamış Yüksek Lisans Tezi). Afyonkarahisar Üniversitesi, Sağlık Bilimleri Enstitüsü, Afyon.

Güngörmüş, H.A., Yenel, F. \& Gürbüz, B. (2014). Bireyleri Rekreasyonel Egzersize Güdüleyen Faktörlerin Belirlenmesi: Demografik Farkl1lıklar. International Journal of Human Sciences, 11(1), 373-386.

Hattie, J.A.,Myers, J.E. \&Sweeney, T.J. (2004). A FactorStructor Of Wellness: Theory, Assessment, Analysis, andPractise. Journal of Counselingand Development, 82(3), 354-364.

Hausenblas, H.A.,Brewer, B.W. \&Raalte, J. (2004) Self-Presentation andExercise. Journal of AppliedSportPsychology, 16(1), 3-18.

Ingledew, D.K.,\&Markland, D. (2008). The Role of Motives in ExerciseParticipation. PsychologyandHealth, 23(7), 807-828.

İlhan, E.L. \& Gencer, E. (2013). Liselerarası Badminton Müsabakalarına Katılan Sporcu Öğrencilerin Spora Katılım Motivasyonlarının Belirlenmesi. Gazi Beden Eğitimi ve Spor Bilimleri Dergisi, 18(1-4), 1-6.

İlhan, E.L. (2009). Voleybolda Servis Becerisi Öğretimine Motivasyonel Bir Yaklaşım. Niğde Üniversitesi Beden Eğitimi ve Spor Bilimleri Dergisi, 3(3), 196-203.

Kartal, Z., Güvendi, B., Türksoy, A. \& Altıncı, E.E. (2017). Takım Sporcularının İmgeleme Kullanımları İle Başari Motivasyonları Arasındaki İlişki. İstanbul Üniversitesi SporBilimleri Dergisi, 7(1), 41-53. 
Kazak, Z. (2004). A Study on Reliability and Validity of "The Sport Motivation Scale -SMS-" For Turkish Athletes. Hacettepe Journal of Sport Sciences, 15(4), 191-206.

Kılıç, T. \& Balta, T. S. (2019). Üniversite Öğrencilerinin Sağlıklı Yaşam Biçimi Davranışlarının İncelenmesi. TurkishStudies, 14(1), 425-438.

Kingston, K.M.,Horrocks, C.S. \&Hanton, S. (2006). Do MultidimensionalİntrinsicandExtrinsicMotivationProfilesDiscriminateBetweenAthleteScholar shipStatusAndGender? Eur J SportSci, 6(1), 53-63.

Owen, K.F., Çelik, D.N. \& Doğan, T. (2017). Üniversite Öğrencilerinde Iyilik Halinin Yordayıcıs1 Olarak Psikolojik Sağlamlık. Elektronik Sosyal Bilimler Dergisi,16(64), 1461-1479.

Markland, D. \&Tobin, V. (2004). A Modification of TheBehavioralRegulation in ExerciseQuestionnairetoInclude An Assessment of Amotivation. J SportExercPsychol, 26(2), 191-196.

Morgan, T.C. (2005). Psikolojiye Giriş. Ankara: Eğitim Kitapevi.

Mullen, E., Markland, D. \&Ingledew, D.K. (1997). A Graded Conceptualization of Self-Determination in The Regulation of Exercise Behavior: Development of A Measure Using Confirmatory Factor Analysis Procedures. PersIndiv Differ,23(5), 745-52.

Odabaş, İ. (2017). TheTurkish Language Adaptation of TheWellness Self-PerceptionsScale: A ValidityandReliabilityStudy. International Journal of Business andSocialScience,8(6), 42-49.

Özdemir, O.,Özşaker, M. \& Ersöz, G. (2016). Serbest Zaman Etkinliği Olarak Egzersiz Yapan Üniversite Öğrencilerinde Güdüsel Yönelim ve Psikolojik Iyi Oluş Ilişkisi. TurkishInternationalJournal of Special EducationandGuidance\& Counseling,5(2), 13-22.

Özdemir, R A.,Cuğ, M. \& Çelik, Ö. (2010) Genç Yetişkin Üniversite Öğrencilerinde Farklı Türde Egzersiz Uygulamalarının Sosyal Fizik Kaygı Düzeyine Etkisi. Spor Bilimleri Dergisi, 21(2), 60-70.

Pelletier, L.G.,Fortier, M.S., Vallerand, R.J., Tuson, K.M. \&Brière, N.M. (1995). Toward A New Measure of IntrinsicMotivation, ExtrinsicMotivation, andAmotivation in Sports: TheSportMotivationScale (SMS). J SportExercPsychol,17(1), 35-53.

Steward, J.L. (1998) Reliabilityandvalidity of theTestwell: Wellness Inventory-High School Edition (Yayımlanmamış Doktora Tezi). Middle Tennessee StateUniversity U.S.A.

Tekkurşun-Demir, G. \& Cicioğlu, H.İ. (2018). Fiziksel Aktiviteye Katılım Motivasyonu Ölçeği (FAKMÖ): Geçerlik ve Güvenirlik Çalışması. Journal of Human Sciences, 15(4), 2479- 2492.

Tekkurşun-Demir, G. \& Türkeli, A. (2019). Spor Bilimleri Fakültesi Öğrencilerinin Egzersiz Bağımlılı̆̆ı ve Zihinsel Dayanıklılık Düzeylerinin İncelenmesi. Spor Bilimleri Araştırmaları Dergisi.

Tekkurşun-Demir, G., Hazar, Z. \& Can, B. (2018). Lise Öğrencilerinin Spora Katılım Güdülerinin Farklı Değişkenler Açısından İncelenmesi. Spormetre, 16(4), 225-235.

Tekkurşun-Demir, G., İlhan, L.E., Esentürk, O. \& Kan, A. (2018). Engelli bireylerde spora katılım motivasyonu ölçeği (ESKMÖ): Geçerlik ve güvenirlik çalışması, Spormetre, 16(1), 91-102.

Toros, T., Akyüz, U., Bayansalduz, M. \&Soyer, F. (2010). Examining The Relationship Between Task-And Ego-Oriented Goals And Life Satisfaction (Astudy of People Doing Mountaineering Sports). International Journal of Human Sciences, 7(2), 1040-1050. 
Türksoy-Işım, A., Güvendi, B. \& Toros, T . (2019). Amatör Lig Futbolcularında Sporda Ahlaktan Uzaklaşma, Güdüsel İklim ve Karar Verme. International Journal of SocialSciencesandEducationResearch, 5(1), 54-62.

Vallerand, R.J. (2000). DeciandRyan's Self-DeterminationTheory: A ViewFromTheHierarchical Model of İntrinsicandExtrinsicMotivation. PsycholInq, 11(4), 312-318.

Wininger, S.R. (2007). Self-DeterminationTheoryandExerciseBehavior: An Examination of ThePsychometricProperties of TheExerciseMotivationScale. Journal of AppliedSportPsychology, 19, 471-486. 